\title{
PHOTOBIOMODULATION IN THE SCARATION OF DEISCENCE AFTER MASTECTOMY: CASE REPORT
}

Nayara A. F. Lemos ${ }^{1,2}$, Ruffo Freitas-Junior ${ }^{1}$, Fernanda D. Moraes ${ }^{2,3}$, Arethuzza A. Moreira ${ }^{4}$, Karla F. Carmo ${ }^{5}$, Alexandre L. Cardoso ${ }^{5}$, Eliceia M. Batista ${ }^{6}$

'Universidade Federal de Goiás - Goiânia (GO), Brazil.

¿Universidade Paulista - Goiânia (GO), Brazil.

${ }^{3}$ Faculdades Objetivo - Goiânia (GO), Brazil.

${ }^{4}$ Associação de Combate ao Câncer de Goiás, Hospital Araújo Jorge - Goiânia (GO), Brazil.

${ }^{5}$ Faculdade Cambury - Goiânia (GO), Brazil.

${ }^{6}$ Hospital das Clínicas de Goiânia - Goiânia (GO), Brazil.

The effects of photobiomodulation on healing occur through the influence of chemical mediators, migration of inflammatory cells and increase of growth factors. Studies emphasize the efficacy in different animal models, however, dosimetric parameters are discrepant. Therefore, the objective of the study is to show a therapeutic option for the treatment of this wound to optimize the other stages of the treatment. This case report refers to a 40-year-old female patient diagnosed with mammary carcinoma followed by confirmation of gestation. The patient had gestational diabetes and on the day of delivery underwent modified radical mastectomy and right axillary lymphadenectomy that evolved with a dehiscence near the axillary cavus. In the evaluation, the patient's main complaint was related to poor healing of the surgical wound and impediment to the start of radiotherapy. A photographic record of the region was carried out, besides a qualitative evaluation of the dehiscence that presented hyperemic, edemaciated and retracted borders. In the main complaint, two physical therapy sessions were performed with a light emitting diode (LEDs) at two wavelengths $470 \mathrm{~nm}$ (blue) and 630 $\mathrm{nm}$ (red) at $5 \mathrm{~J} / \mathrm{cm} 2$ and the 19 seconds and 1:30 minutes respectively. Resolution was observed in the surgical dehiscence. Photobiomodulation proves to be an important resource for the treatment of dehiscence after mastectomy. 